\title{
INFLUÊNCIA DA PRECIPITAÇÃO E TEMPERATURA DO AR NA PRODUÇÃO DE SERAPILHEIRA EM TRECHO DE FLORESTA ESTACIONAL EM SOROCABA, SP
}

\author{
Rafael Nogueira Scoriza ${ }^{1}$, Fatima Conceição Márquez Piña-Rodrigues ${ }^{2}$ \\ ${ }^{1}$ Biólogo, Doutorando em Agronomia - Ciência do Solo, UFRRJ, Seropédica, RJ, Brasil - rafaelscoriza@gmail.com \\ ${ }^{2}$ Eng $^{\text {a }}$. Florestal, Dr ${ }^{\text {. }}$, UFSCAR, Sorocaba, SP, Brasil - fpina@ ufscar.br
}

Recebido para publicação: 08/11/2013 - Aceito para publicação: 01/05/2014

\begin{abstract}
Resumo
A fragmentação e destruição da Mata Atlântica tornam a sua conservação fundamental. A serapilheira é um importante componente desse sistema e apresenta diferenças na deposição nos diferentes ecossistemas brasileiros. Com isso, o objetivo deste estudo foi avaliar o efeito da precipitação e da temperatura do ar no aporte de serapilheira em fragmentos florestais localizados em Sorocaba, SP. A quantidade média de serapilheira aportada foi de $6,9 \pm 0,4 \mathrm{mg} \cdot \mathrm{ha}^{-1} \cdot \mathrm{ano}^{-1}$, formada por $65 \%$ de folhas. Houve diferenças entre as deposições nas estações do ano, sendo que a menor quantidade foi depositada no período seco. A correlação da serapilheira e suas frações não foram significativas quando analisada para o mesmo mês da avaliação da temperatura do ar e precipitação. Porém, quando se relacionam meses anteriores, a correlação é mais expressiva, demonstrando que a resposta da vegetação a variações ambientais não é imediata.

Palavras-chave: Clima; sazonalidade; Mata Atlântica.
\end{abstract}

\begin{abstract}
Influence of precipitation and air temperature in production of litterfall in stretch of seasonal forest. Fragmentation and destruction of the Atlantic Rainforest make its conservation essential. The litter is an important component of this system, and reveals differences in deposition in the different Brazilian ecosystems. This research aims to evaluate the effect of rainfall and air temperature on litterfall input in a forest fragment at the municipality of Sorocaba, São Paulo State, Brazil. The average contribution of litterfall was $6.9 \pm 0.4 \mathrm{Mg} \mathrm{ha}^{-1} \mathrm{yr}^{-1}$, comprising $65 \%$ of leaves. There were differences between the seasons, with the less amount in the dry season. The correlation of litter and its fractions was not relevant for the same month of air temperature and rainfall measurement. However, the correlation is significant when related to the previous month, demonstrating that the response of vegetation to environmental changes is not immediate.

Keywords: Climate; seasonality; Atlantic forest.
\end{abstract}

\section{INTRODUÇÃO}

Entre os ecossistemas mais ameaçados em todo o mundo, a cobertura remanescente da Mata Atlântica restringe-se a apenas 7\% de sua área original (MORAES et al., 2013). Segundo o Ministério do Meio Ambiente (MMA), com séculos de destruição, estima-se sua redução a apenas $300 \mathrm{mil} \mathrm{km}^{2}$ de fragmentos florestais, especialmente da formação estacional (MMA, 2010). Esse quadro de degradação afeta não apenas a biodiversidade e a interação entre as espécies, mas também muitas das suas funções e características, como os ciclos hidrológicos e bioquímicos, a biomassa florestal e o estoque de carbono (LAURANCE et al., 2011).

A região de Sorocaba detém a segunda maior concentração de fragmentos florestais do estado de São Paulo e se caracteriza como uma zona ecotonal, com intersecção de Floresta Estacional, Ombrófila Mista e Densa com áreas de Cerrado (ALBUQUERQUE; RODRIGUES, 2000; INSTITUTO FLORESTAL, 2005). Denota-se assim grande importância no cenário de conservação florestal, sendo necessário para isso um prolongado e intenso estudo das características bióticas e abióticas desses remanescentes. 
No sistema florestal, a serapilheira é um importante componente, representando o material precipitado ao solo, que inclui principalmente folhas, caules, frutos, sementes, flores e resíduos animais (COSTA et al., 2010). Sua produção e ciclagem de nutrientes podem variar de acordo com o grau de conservação, idade e composição do sistema florestal e diversos fatores bióticos e abióticos (ARAÚJO et al., 2006; CALVI et al., 2009; DICKOW et al., 2012; VENDRAMI et al., 2012).

Existem dois padrões básicos para a deposição anual de serapilheira nos ecossistemas brasileiros: o primeiro é caracterizado pela maior deposição na época seca, como ocorre em ecossistemas amazônicos, nas florestas mesófilas e cerrados; o segundo consiste em um aumento na intensidade da deposição de serapilheira na época úmida, típico das florestas atlânticas e restingas (CATTANIO et al., 2004; CIANCIARUSO et al., 2006; ARAÚJO et al., 2006; PIRES et al., 2006). Vários são os fatores que podem estar determinando esses fenômenos. A temperatura é um dos mais importantes fatores ambientais, sendo que sua variabilidade ao longo do dia, estações e ano determina o desenvolvimento e o comportamento dos seres vivos. A precipitação é determinada principalmente pela geografia e pelo padrão de grandes movimentos do ar ou de sistemas de condições meteorológicas. Representa a entrada de água no sistema, que é um fator necessário fisiologicamente para todos os seres vivos (ODUM; BARRETT, 2011).

Para Moreira e Silva (2004), a maior deposição ocorre em decorrência ao estresse hídrico, indicado pela ocorrência de picos na estação seca. Já Brun et al. (2001) ressaltaram a influência dos fatores genéticos de adaptação das espécies a condições meteorológicas locais. Com isso, o objetivo deste trabalho foi avaliar o efeito das variáveis temperatura do ar e precipitação no aporte de serapilheira em áreas de Floresta Estacional Semidecidual em Sorocaba, São Paulo.

\section{MATERIAL E MÉTODOS}

A pesquisa foi realizada em cinco fragmentos florestais localizados a $23^{\circ} 34^{\prime \prime} \mathrm{S}$ e $47^{\circ} 31^{\prime}$ W, nas proximidades do rio Ipaneminha (intermitente que desde o início do estudo encontra-se sem água ao longo de todo ano), integrante da bacia do rio Sorocaba e Médio Tietê, a uma altitude média de 660 metros, no município de Sorocaba, SP. Os fragmentos estudados são contínuos entre si e medem: F1 - 4,5 ha, F2 - 1,68 ha, F3 - 4,75 ha, F4 - 4,16 ha e F5 - 1,54 ha, cercados por pastagem com Brachiaria decumbens L. e Melinis minutiflora L. (Figura 1).

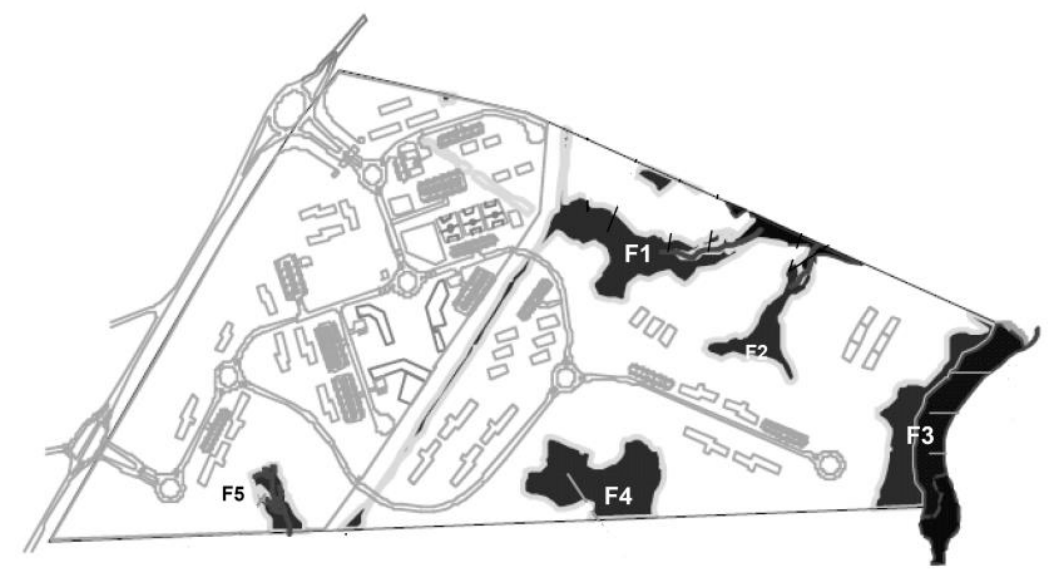

Figura 1. Localização e distribuição dos fragmentos e parcelas na área de estudo em Sorocaba, SP. (Fonte: banco de dados UFSCar Sorocaba). F1-F5 - Fragmentos.

Figure 1. Location and distribution of fragments and plots in the focused area in Sorocaba, SP. (Source: database UFSCar Sorocaba). F1-F5 - Fragments.

A vegetação predominante da área é a Floresta Estacional Semidecidual, em estádio secundário, com intersecções de Cerrado. O clima foi classificado como $C f a$, caracterizado por longa estação seca sazonal (ALBUQUERQUE; RODRIGUES, 2000). Os dados meteorológicos foram fornecidos pelo Instituto Nacional de Meteorologia (INMET), $7^{\circ}$ Distrito de Meteorologia, Sorocaba, SP (Figura 1). Segundo classificação da Empresa Brasileira de Pesquisa Agropecuária (EMBRAPA), o solo predominante é o Latossolo Eutroférrico (EMBRAPA, 2013). Para a amostragem, foram delimitadas 10 
parcelas de $10 \times 10$ metros, distribuídas ao acaso nos fragmentos. Em cada parcela foram instalados, diagonalmente e equidistantes, três coletores cônicos de tecido helanca, com área de $0,25 \mathrm{~m}^{2}$ de abertura, a $1,30 \mathrm{~m}$ do solo.

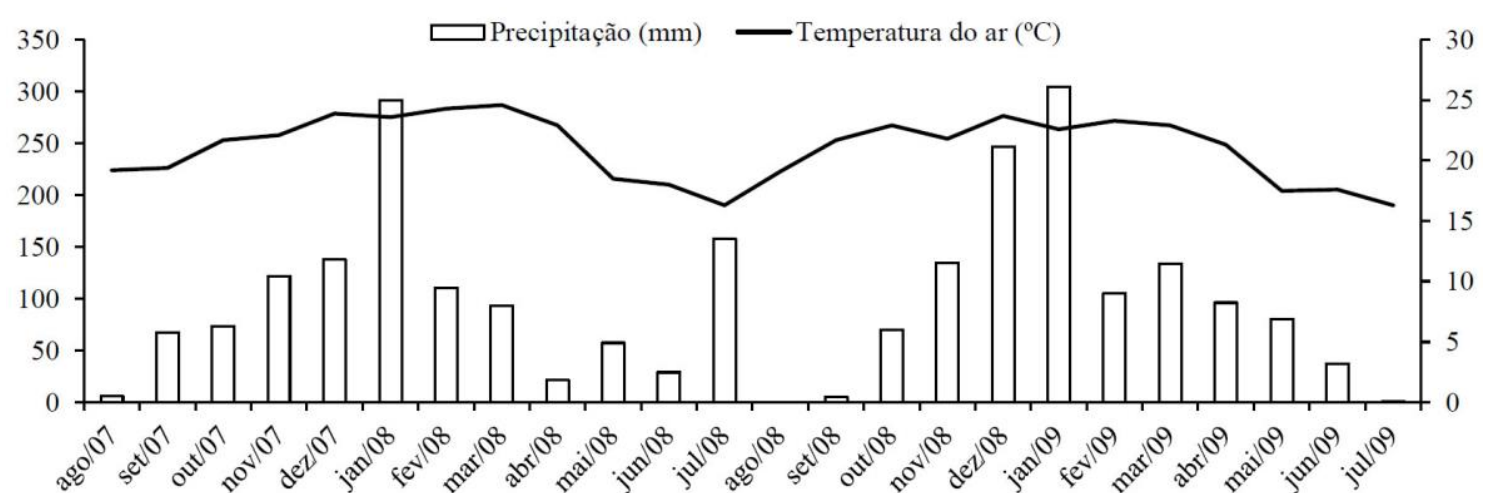

Figura 2. Média mensal de 47 anos da precipitação ( $\mathrm{mm} / \mathrm{mês})$ e temperatura $\left({ }^{\circ} \mathrm{C}\right)$ da região de Sorocaba, SP.

Figure 2. Monthly average of 47 years of rainfall $(\mathrm{mm} / \mathrm{month})$ and temperature $\left({ }^{\circ} \mathrm{C}\right)$ in Sorocaba, Brazil.

As coletas foram efetuadas mensalmente desde agosto de 2007 até julho de 2009. Nos coletores, a serapilheira foi retirada e acondicionada em sacos plásticos identificados. Em laboratório, o conteúdo foi submetido a pré-secagem por dois a três dias e separado nas frações de folhas, ramos, material reprodutivo e material não identificável. Cada fração foi secada em estufa a $65{ }^{\circ} \mathrm{C}$ até atingir massa constante e pesada em balança de precisão semianalítica.

A relação entre as médias mensais de temperatura do ar e precipitação e os dados de aporte mensal da serapilheira (total e frações) foi avaliada utilizando-se o coeficiente de correlação de Pearson para os dados de temperatura do ar e precipitação ocorridos no mesmo mês do aporte e de um a seis meses antes. A sazonalidade de produção da serapilheira para as estações seca (abril a setembro) e úmida (outubro a março) foi analisada utilizando-se o teste de qui-quadrado, considerando o total aportado (Mg.ha ${ }^{-1}$ ).

\section{RESULTADOS E DISCUSSÃO}

A quantidade de serapilheira aportada nos fragmentos florestais foi $6,9 \pm 0,4 \mathrm{Mg} \cdot \mathrm{ha}^{-1} \cdot$ ano $^{-1}$, composta por $65 \%$ de folhas, $18 \%$ de ramos, $6 \%$ de material reprodutivo e $11 \%$ de material não identificável. Valores semelhantes são encontrados na literatura para floresta estacional semidecidual, que apresenta variação de 5,09 a 10,6 Mg.ha ${ }^{-1} \cdot$ ano $^{-1}$ (WERNECK et al., 2001; HORA et al., 2008; GODINHO et al., 2013). Alguns autores associam essa variação às características fisiológicas das espécies pioneiras de maior ocorrência nessas áreas, que possuem período e ciclos de vida menores que as espécies clímax, aportando mais frequentemente a serapilheira ao solo (PINTO et al., 2008; HORA et al., 2008; MENEZES et al., 2010; GODINHO et al., 2013).

As folhas normalmente constituem a maior proporção da biomassa de serapilheira que cai ao solo (SCHUMACHER et al., 2011), que neste estudo representou 4,4 Mg.ha ${ }^{-1}$.ano ${ }^{-1}$. Alguns autores consideram que épocas úmidas ao longo do ano provêm condições ambientais mais propícias para a renovação foliar, e sua ação mecânica pode influenciar na queda das folhas (DIAS; OLIVEIRA FILHO, 1997; VENDRAMI et al., 2012).

Outros fatores ambientais, como avançada idade da folha, estresse hídrico, diminuição de entrada de nutrientes, diminuição do período do dia, mudanças na composição dos gases atmosféricos e consumo por organismos parasitas, representam uma grande contribuição para a queda das folhas (ADDICOTT; LYON, 1973; BORCHERT et al., 2002). Além dos aspectos climáticos, devem-se levar em consideração o aspecto dinâmico e sucessional de uma floresta tropical e os hormônios vegetais. Em estudo realizado por Janzen (1980), atribuiu-se a queda das folhas das árvores tropicais, entre outros fatores, à competição pela luz incidente, provocada pelo aumento de sombra dentro e entre copas, tanto nos estádios iniciais da sucessão quanto nos estádios mais avançados. Para Kerbauv (2008), os mecanismos de senescência e abscisão foliar estão relacionados à atividade de uma série de hormônios vegetais, tais como as 
citocininas, as auxinas e o ácido abscísico, que, direta ou indiretamente, promovem um aumento da taxa respiratória relacionada ao crescimento até a queda foliar.

Considerando o aporte mensal (Figura 3) dentro das estações seca e úmida do período do estudo (Figura 4), constata-se que houve sazonalidade na deposição de serapilheira $\left(\chi^{2}=34,5 ; p<0,01\right)$, com média aportada na estação úmida (outubro a março) de $0,7 \mathrm{Mg} \cdot \mathrm{ha}^{-1} \cdot$ mês $^{-1}$ e $0,5 \mathrm{Mg} \cdot \mathrm{ha}^{-1} \cdot$ mês $^{-1}$ na seca (abril a setembro).

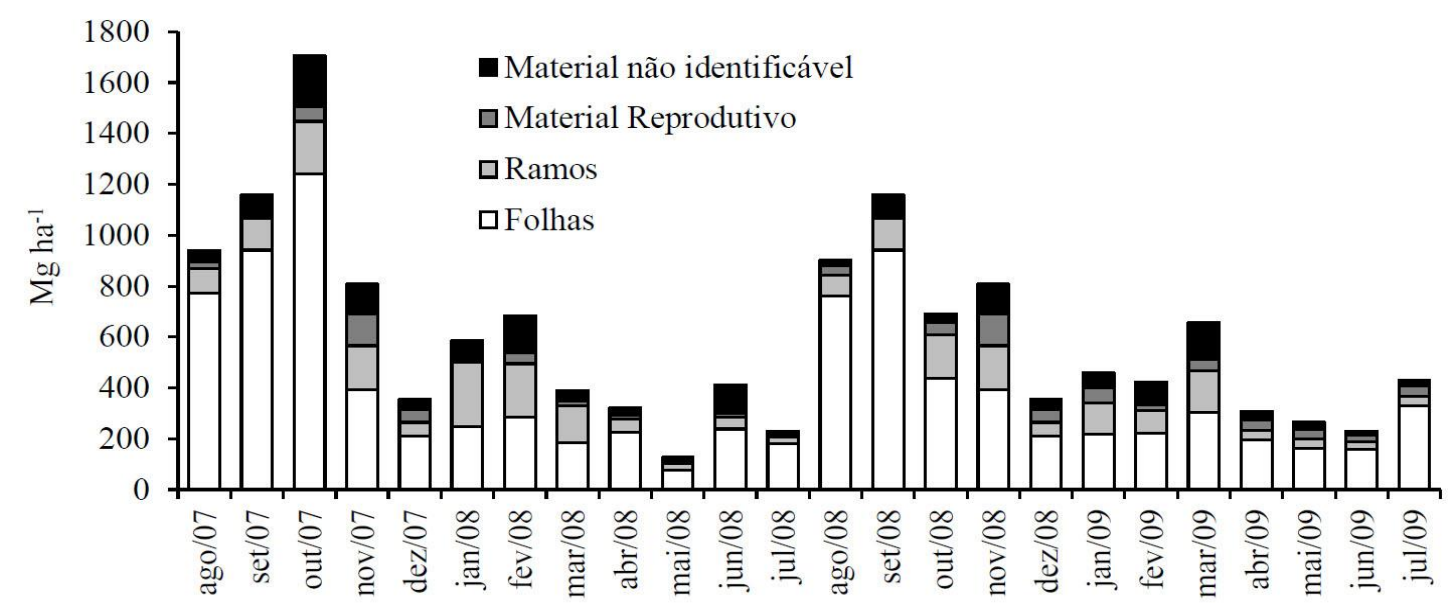

Figura 3. Aporte mensal médio de serapilheira em fragmentos florestais de Sorocaba, SP.

Figure 3. Average monthly contribution of litter in forest fragments of Sorocaba, SP.

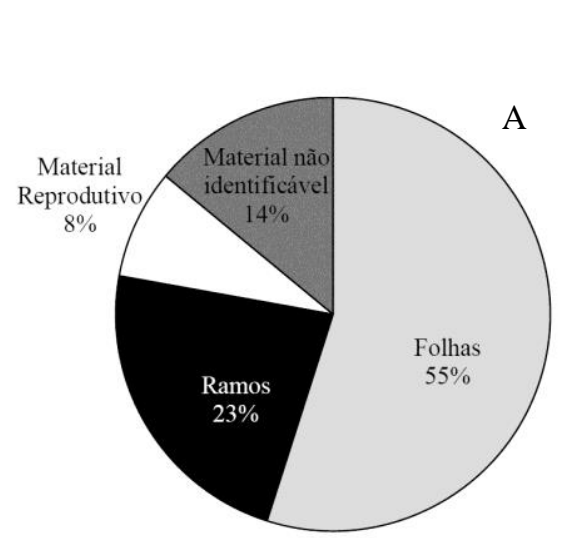

Estação úmida (outubro - março)

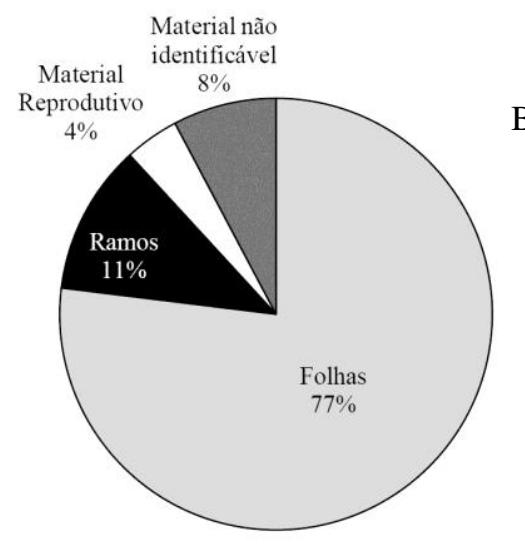

Estação seca (abril - setembro)

Figura 4. Aporte de serapilheira nos períodos úmido (a) e seco (b) em fragmentos florestais de Sorocaba, SP. Figure 4. Literfall in humid (a) and dry (b) periods in forest fragments in Sorocaba, SP.

O maior aporte relativo de folhas ocorreu no período seco (77\%) (Figura 4), sendo a maior deposição total obtida no mês em outubro de 2007 (1239,62 Mg.ha ${ }^{-1}$ ) (Figura 3). Esse padrão não foi observado por alguns autores (HORA et al., 2008; JARAMILLO-BOTERO et al., 2008; MACHADO et al., 2008; GODINHO et al., 2013), porém outros autores encontraram picos de deposição total na estação seca (CIANCIARUSO et al., 2006; SILVA et al., 2007). Segundo Dias e Oliveira Filho (1997), espera-se uma variação sazonal na deposição de serapilheira, em virtude das diferenças nas condições ambientais ao longo do ano, principalmente de precipitação. Esses autores encontraram, para uma floresta estacional semidecídua em Lavras (MG), uma maior deposição de serapilheira na estação chuvosa, que, segundo os autores e Vendrami et al. (2012), pode estar associada à ação mecânica realizada pelas chuvas e ventos. 


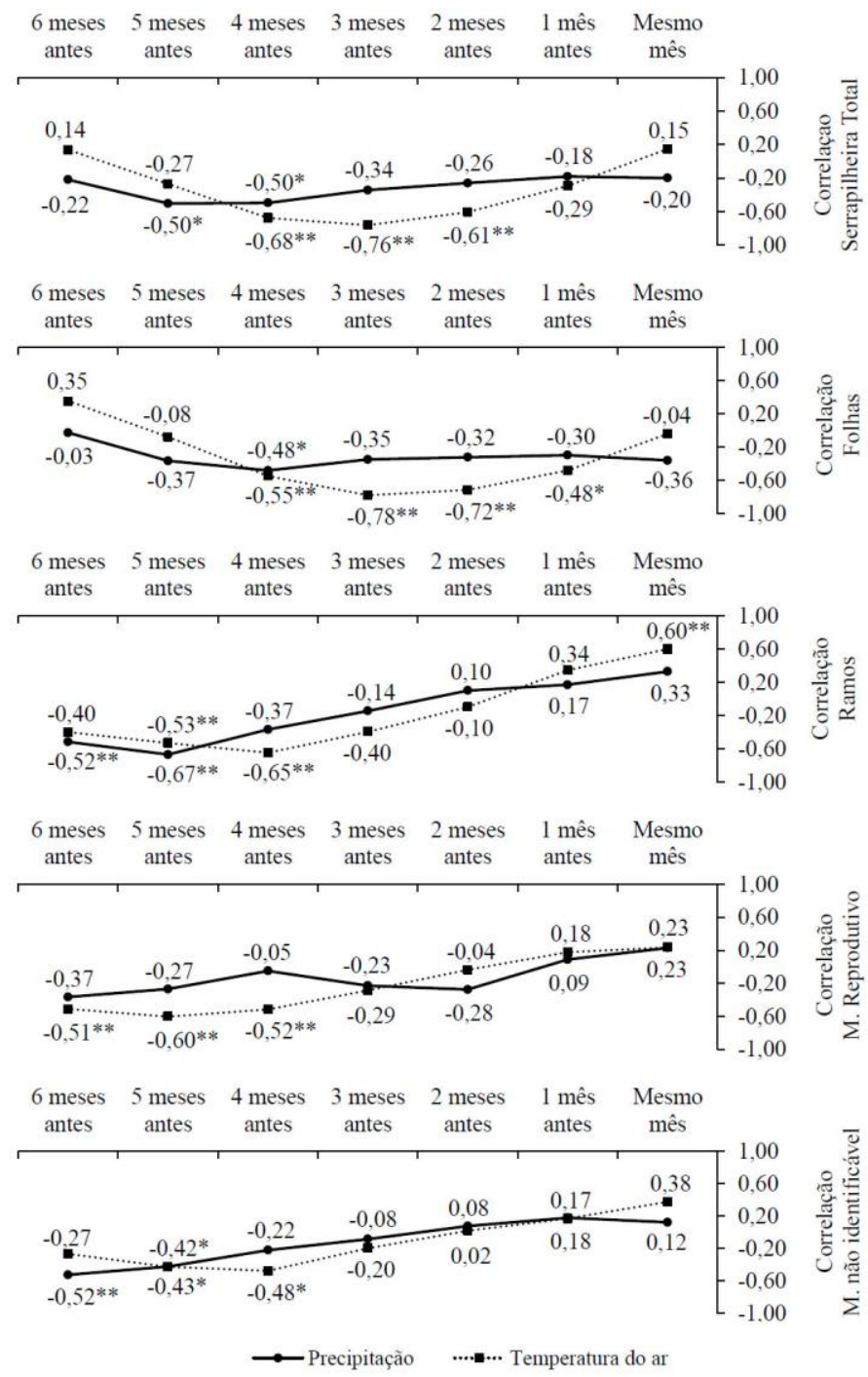

Figura 5. Análise de correlação do aporte de serapilheira nos fragmentos florestais de Sorocaba, SP, com a precipitação $(\mathrm{mm})$ e temperatura do ar $\left({ }^{\circ} \mathrm{C}\right)$ ocorridos no mesmo mês e 30, 60, 90, 120 e 180 dias antes. Os asteriscos indicam significância de correlação de Pearson a 5\% (*) e 1\% (**).

Figure 5. Correlation analysis of the contribution of litter in forest fragments of Sorocaba, SP, rainfall $(\mathrm{mm})$ and temperature $\left({ }^{\circ} \mathrm{C}\right)$ occurred in the same months and 30,60, 90, 120 and 180 days before. Asterisks indicate significance Pearson correlation to 5\% (*) and 1\% (**).

Alguns estudos apontam que existe relação da deposição de serapilheira com fatores climáticos (OLIVEIRA; LACERDA, 1993; MARTINS; RODRIGUES, 1999; SANTOS; VÁLIO, 2002), porém essa correlação costuma ser fraca e imprecisa. Estudo realizado por Brun et al. (2001), avaliando a influência do clima sobre a serapilheira, encontraram em grande parte baixas correlações para todos os fatores analisados (precipitação, temperatura, umidade relativa, velocidade do vento e evapotranspiração) em todos os estádios sucessionais (capoeirão, floresta secundária e floresta madura), concluindo que a deposição de serapilheira é pouco influenciada pela precipitação, sendo mais influenciada pela temperatura. Em avaliações feitas por Vogel et al. (2007) ao encontrarem baixas correlações entre a serapilheira e suas frações e as variáveis climáticas, afirmam que o uso somente das variáveis climáticas temperatura média e precipitação mensal pode não ser suficiente, sendo necessário o uso de mais variáveis climáticas, como, por exemplo, velocidade de ventos e direção, ocorrência de tempestades no local, bem como um período maior do que dois anos de observação, como realizado por Menezes et al. (2010). Contudo, no presente estudo, essa correlação ficou 
mais clara quando foram analisadas as relações entre a deposição de cada mês e os fatores climáticos ocorrentes no mesmo mês e nos anteriores (Figura 5).

Segundo Arato et al. (2003), pode haver atraso de cerca de dois meses para a resposta da vegetação ao estresse hídrico. Confirmando o proposto por esses autores, nos fragmentos estudados foi constatado que a temperatura e a precipitação não influenciaram imediatamente o aporte de serapilheira, mas apresentaram seus efeitos mais significativos alguns meses depois. Essa afirmação baseia-se na ausência de correlações significativas entre a serapilheira e a precipitação ou temperatura no mesmo mês, com uma única exceção para a relação entre ramos e temperatura $(\mathrm{r}=0,60)$. Para a temperatura, a maior correlação observada foi entre a fração folhas e a temperatura ocorrida três meses antes $(r=-0,78)$. No caso da precipitação, destacou-se a relação entre a fração ramos e a precipitação ocorrida cinco meses antes $(r=-0,67)$. $O$ padrão observado para o aporte total foi similar ao obtido para a fração folhas, uma vez que esse componente da serapilheira é o mais representativo, o que se refletiu no padrão obtido. Em trabalho semelhante, Araújo et al. (2006) destacaram que a maior taxa mensal de deposição da fração ramos (janeiro) ocorreu quatro meses após o período de seca, denotando o efeito do estresse hídrico.

Deve-se destacar que a maioria das correlações apresentando valores mais altos e significativos $(r \geq 0,42)$ foi negativa, indicando a tendência de menor aporte de serapilheira e seus componentes com o incremento da temperatura e da precipitação. As respostas aos fatores ambientais foram distintas para as frações, com um efeito mais imediato no mesmo mês (efeito físico) e mais tardio constatado nos meses subsequentes (efeito fisiológico), porém enfatiza a importância da temperatura do ar e da precipitação como desencadeadores do aporte de biomassa. Corroborando esses resultados, outros autores encontraram correlações entre fatores climáticos e o aporte de serapilheira total e suas frações (Tabela 1).

Tabela 1. Revisão da literatura mostrando análises de correlação entre variáveis meteorológicas e a serapilheira total e suas frações.

Table 1. Review of literature on correlation analyzes between meteorological variables with the total litter and its fractions.

\begin{tabular}{|c|c|c|c|c|}
\hline Autor & Vegetação & Fator climático & Serrapilheira & Correlação \\
\hline \multirow[t]{2}{*}{ Araújo et al., 2006} & \multirow{2}{*}{$\begin{array}{l}\text { Floresta Ombrófila Densa } \\
\text { (Mata Secundária) }\end{array}$} & Temperatura & Miscelânea & 0,63 \\
\hline & & Precipitação & Total & $-0,69$ \\
\hline Brun et al., 2001 & $\begin{array}{c}\text { Floresta Estacional Decidual } \\
\text { (Floresta Madura) }\end{array}$ & Velocidade vento & Folhas & 0,74 \\
\hline Fernandes et al., 2007 & & Precipitação & Folhas & $-0,50$ \\
\hline $\begin{array}{l}\text { Figueiredo Filho et } \\
\text { al., } 2005\end{array}$ & Floresta Ombrófila Mista & Precipitação & Total & 0,61 \\
\hline \multirow[t]{2}{*}{ Konig et al., 2002} & \multirow[t]{2}{*}{ Floresta Estacional Decidual } & Temperatura & Total & 0,54 \\
\hline & & Temperatura & Total & $-0,52$ \\
\hline \multirow{3}{*}{$\begin{array}{l}\text { Pezzato; Wisniewski, } \\
2006\end{array}$} & \multirow{3}{*}{$\begin{array}{l}\text { Floresta Ombrófila Mista } \\
\text { (Capoeirão) }\end{array}$} & Velocidade vento & Total & 0,68 \\
\hline & & Velocidade vento & Total & 0,52 \\
\hline & & Umidade relativa & Total & 0,52 \\
\hline \multirow[t]{6}{*}{ Godinho et al., 2013} & \multirow[t]{6}{*}{ Floresta Estacional Decidual } & Temperatura & Miscelânea & 0,26 \\
\hline & & Precipitação & & $-0,14$ \\
\hline & & Temperatura & Total & 0,26 \\
\hline & & Precipitação & & $-0,14$ \\
\hline & & Temperatura & Galhos & 0,47 \\
\hline & & Precipitação & & 0,08 \\
\hline Vogel et al., 2007 & & Temperatura & Miscelânea & 0,46 \\
\hline
\end{tabular}

\section{CONCLUSÃO}

- As variáveis climáticas apresentam maiores efeitos na deposição de serapilheira quando considerado o fenômeno de precipitação e/ou temperatura do ar de alguns meses anteriores à sua ocorrência, demonstrando que a resposta da vegetação a variações ambientais não é imediata. Além disso, destaca-se a influência das condições climáticas na fenologia e ciclagem de nutrientes na floresta estacional. 


\section{REFERÊNCIAS}

ALBUQUERQUE, G. B; RODRIGUES, R. R. A vegetação do morro de Araçoiaba, Floresta Nacional Ipanema, Iperó, SP. Scientia Forestalis, Piracicaba, v. 58, p. 145 - 159, 2000.

ADDICOTT, F. T.; LYON, J. L. Physiological ecology of abscission. In: KOZLOWSKI, T. T. (Ed.). Physiological ecology: a series of monographs, texts and treatises. Academic Press: New York, 1973.

ARATO, H. D.; MARTINS, S. V.; FERRARI, S. H. S. Produção e decomposição de serapilheira em um sistema agroflorestal implantado para recuperação de área degradada em Viçosa, MG. Revista Árvore, Viçosa, v. 27, n. 5, p. 715 - 721, 2003.

ARAÚJO, R. S.; PIÑA-RODRIGUES, F. C. M.; MACHADO, M. R.; PEREIRA, M. G.; FRAZÃO, F. J. Aporte de serapilheira e nutrientes ao solo em três modelos de revegetação na Reserva Biológica de Poços das Antas, Silva Jardim, RJ. Floresta e Ambiente, Seropédica, v. 12, n. 2, p. 15 - 21, 2006.

BORCHERT, R.; RIVERA, G.; HAGNAUER, W. Modification of vegetative phenology in a tropical semi-deciduous forest by abnormal drought and rain. Biotropica, São Paulo, v. 34, p. 27 - 39, 2002.

BRUN, E. J.; SCHUMACHER, M. V.; SPATHELF, P. Relação entre a produção de serapilheira e variáveis meteorológicas em três fases sucessionais de uma Floresta Estacional Decidual no Rio Grande do Sul. Revista Brasileira de Agrometeorologia, Piracicaba, v. 9, n. 2, p. 277 - 285, 2001.

CALVI, G. P.; PEREIRA, M. G.; ESPÍNDULA JÚNIOR, A. Produção de serapilheira e aporte de nutrientes em áreas de floresta atlântica em Santa Maria de Jetibá, ES. Ciência Florestal, Santa Maria, v. 19, n. 2, p. $131-138,2009$.

CATTANiO, J. H.; ANDERSON, A. B.; ROMBOLD, J. S.; NEPSTAD, D. C. Phenology, litterfall, growth, and root biomass in a tidal floodplain forest in the Amazon estuary. Revista Brasileira de Botânica, São Paulo, v. 27, n. 4, p. 703 - 712, 2004.

CIANCIARUSO, M. V.; PIRES, J. S. R.; DELITTI, W. B. C.; SILVA, E. F. L. P. Produção de serapilheira e decomposição de material foliar em um cerradão na Estação Ecológica de Jataí, município de Luiz Antônio, SP, Brasil. Acta Botânica Brasílica, Feira de Santana, v. 20, n. 1, p. 49 - 59, 2006.

COSTA, C. C. A.; CAMACHO, R. G. V.; MACEDO, I. D.; SILVA, P. C. M. Análise comparativa da produção de serapilheira em fragmentos arbóreos e arbustivos em área de Caatinga na Flona de Açu, RN. Revista Árvore, Viçosa, v. 34, n. 2, p. 259 - 265, 2010.

DIAS, H. C. T.; OLIVEIRA FILHO, A. T. Variação temporal e espacial da produção de serapilheira em uma área de floresta estacional semidecídua Montana em Lavras-MG. Revista Árvore, Viçosa, v. 21, n. 1 , p. $11-26,1997$.

DICKOW, K. M. C.; MARQUES, R.; PINTO, C. B.; HOFER, H. Produção de serapilheira em diferentes fases sucessionais de uma floresta subtropical secundária, em Antonina, PR. Revista Cerne, Lavras, v. 18, n. 1, p. 75 - 86, 2012.

EMPRESA BRASILEIRA DE PESQUISA AGROPECUÁRIA (EMBRAPA). Sistema Brasileiro de Classificação de Solos. 3. ed. rev. ampl. Brasília: Embrapa, 2013. 306 p.

FERNANDES, M. E. B.; NASCIMENTO, A. A. M.; CARVALHO, M. L. Estimativa da produção anual de serapilheira nos bosques de mangue no Furo Grande, Bragança, Pará. Revista Árvore, Viçosa, v. 31, n. 5, p. 949 - 958, 2007.

FIGUEIREDO FILHO, A.; SERPE, E. L.; BECKER, M.; SANTOS, D. F. Produção estacional de serapilheira em uma Floresta Ombrófila Mista na Floresta Nacional de Irati (PR). Ambiência, Guarapuava, v. 1, n. 2, p. 257 - 269, 2005.

GODINHO, T. de O.; CALDEIRA, M. V. W.; CALIMAN, J. P.; PREZOTTI, L. C.; WATZLAWICK, L. F.; AZEVEDO, H. C. A.; ROCHA, J. H. T. Biomassa, macronutrientes e carbono orgânico na serapilheira depositada em trecho de Floresta Estacional Semidecidual Submontana, ES. Scientia Forestalis, Piracicaba, v. 41, n. 97, p. 131 - 144, 2013. 
HORA, R. C.; PRIMAVESI, O.; SOARES, J. J. Contribuição das folhas de lianas na produção de serapilheira em um fragmento de floresta estacional semidecidual em São Carlos, SP. Revista Brasileira de Botânica, São Paulo, v. 31, n. 2, p. 277 - 285, 2008.

INSTITUTO FlORESTAL. Inventário Florestal da Vegetação Natural do Estado de São Paulo. Secretaria do Meio Ambiente/Instituto Florestal: São Paulo; 2005.

JANZEN, D. H. Tropical dry forest: The most endangered major tropical ecosystem. In: WILSON, E. O.; PETER, F. M. (Eds.). Biodiversity. National Academy Press: Washington, D.C., 1980.

JARAMILLO-BOTERO, C.; SANTOS, R. H. S.; FARDIM, M. P.; PONTES, T. M.; SARMIENTO, F. Produção de serapilheira e aporte de nutrientes de espécies arbóreas nativas em um sistema agroflorestal na Zona da Mata de Minas Gerais. Revista Árvore, Viçosa, v. 32, n. 5, p. 869 - 877, 2008.

KERBAUV, G. B. Fisiologia Vegetal. 2. ed. Rio de Janeiro: Guanabara Koogan, 2008.

KONIG, F. G.; SCHUMACHER, M. V.; BRUN, E. J.; SELING, I. Avaliação da sazonalidade da produção de serapilheira numa floresta estacional decidual no município de Santa Maria, RS. Revista Árvore, Viçosa, v. 26, n. 4, p. 429 - 435, 2002.

LAURANCE, W. F.; CAMARGO, J. L. C.; LUIZÃO, R. C. C.; LAURANCE, S. G.; PIMM, S. L.; BRUNA, E. B.; STOUFFER, P. C.; WILLIAMSO, G. B.; BENÍTEZ-MALVIDO, J.; VASCONELOS, H. L.; VAN HOUTAN, K. S.; ZARTMAN, C. E.; BOYLE, S. A.; DIDHAM, R. K.; ANDRADE, A.; LOVEJOY, T. E. The fate of Amazonian forest fragments: A 32-year investigation. Biological Conservation, Boston, v. 144, p. 56 - 67, 2011.

MACHADO, M. R.; PIÑA-RODRIGUES, F. C. M.; PEREIRA, M. G. Produção de serapilheira como indicador de recuperação em plantio adensado de revegetação. Revista Árvore, Viçosa, v. 32, n. 1, p. 143 - 151, 2008.

MARTINS, S. V.; RODRIGUES, R. R. Produção de serapilheira em clareiras de uma floresta estacional semidecidual no município de Campinas, SP. Revista Brasileira de Botânica, São Paulo, v. 22, p. 3, p. 405 - 412, 1999.

MENEZES, C. E. G.; PEREIRA, M. G.; CORREIA, M. E. F.; ANJOS, L. H. C.; PAULA, R. R.; SOUZA, M. E. Aporte e decomposição da serapilheira e produção de biomassa radicular em florestas com diferentes estágios sucessionais em Pinheiral, RJ. Ciência Florestal, Santa Maria, v. 20, n. 3, p. 439 - 452, 2010.

MINISTÉRIO DO MEIO AMBIENTE/SERVIÇO FLORESTAL BRASILEIRO. Florestas do Brasil em resumo: dados de 2005-2010. Brasília: SFB, 2010.

MORAES, L. F. D.; ASSUMPÇÃO, J. M.; PEREIRA, T. S.; LUCHIARI, C. Manual técnico para a restauração de áreas degradadas no estado do Rio de Janeiro. Jardim Botânico do Rio de Janeiro: Rio de Janeiro, 2013.

MOREIRA, P. R.; SILVA, O. A. Produção de serapilheira em área reflorestada. Revista Árvore, Viçosa, v. 28, n. 1, p. 49 - 59, 2004.

ODUM, E. P.; BARRETT, G. W. Fundamentos de ecologia. 5. ed. São Paulo: Cengage Learning, 2011.

OLIVEIRA, R. R.; LACERDA, L. D. Produção e composição química da serapilheira na floresta da Tijuca (RJ). Revista Brasileira de Botânica, São Paulo, v. 16, n. 1, p. 93 - 99, 1993.

PEZZATO, A. W.; WISNIEWSKI, C. Produção de serapilheira em diferentes seres sucessionais da Floresta Estacional Semidecidual no oeste do Paraná. Floresta, Curitiba, v. 36, n. 1, p. 111 - 120, 2006.

PINTO, S. I. C.; MARTINS, S. V.; BARROS, N. F.; DIAS, H. C. T. Produção de serapilheira em dois estádios sucessionais de floresta estacional semidecidual na reserva Mata do Paraíso, em Viçosa, MG. Revista Árvore, Viçosa, v. 32, n. 3, p. 545 - 556, 2008. 
PIRES, L. A.; BRITEZ, R. M.; MARTEL, G.; PAGANO, S. N. Produção, acúmulo e decomposição da serapilheira em uma restinga da Ilha do Mel, Paranaguá, PR, Brasil. Acta Botânica Brasílica, Feira de Santana, v. 20, n. 1, p. 173 - 184, 2006.

SANTOS, S. L.; VÁLIO, I. F. M. Litter accumulation and its effect on seedling recruitment in a southeast Brazilian Tropical Forest. Revista Brasileira de Botânica, São Paulo, v. 25, n. 1, p. 89 - 92, 2002.

SILVA, C. J.; SANCHES, L.; BLEICH, M. E.; LOBO, F. A.; NOGUEIRA, J. S. Produção de serapilheira no Cerrado e Floresta de Transição Amazônia-Cerrado do Centro-Oeste Brasileiro. Acta Amazônica, Manaus, v. 37, n. 4, p. 543 - 548, 2007.

SCHUMACHER, M. V.; TRÜBY, P.; MARAFIGA, J. M.; VIERA, M.; SZYMCZAK, D. A. Espécies predominantes na deposição de serapilheira em fragmento de Floresta Estacional Decidual no Rio Grande do Sul. Ciência Florestal, Santa Maria, v. 21, n. 3, p. 479 - 486, 2011.

VENDRAMI, J. P.; JURINITZ, C. F.; CASTANHO, C. T. Litterfall and leaf decomposition in forest fragments under different successional phases on the Atlantic Plateau of the state of Sao Paulo, Brazil. Biota Neotropica, v. 12, n. 3, p. 136 - 143, 2012.

VOGEL, A. L. M.; SHUMACHER, M. V.; TRÜBY, P.; VUADEN, E. Avaliação da devolução da serapilheira em uma Floresta Estacional Decidual em Itaara, RS, Brasil. Ciência Florestal, v. 17, n. 3, p. 187 - 196, 2007.

WERNECK, M. S.; PEDRALLI, G.; GIESEKE, L. F. Produção de serapilheira em três trechos de uma floresta semidecídua com diferentes graus de perturbação na Estação Ecológica do Tripuí, Ouro Preto, MG. Revista Brasileira de Botânica, v. 24, n. 2, p. 195 - 198, 2001. 

Scoriza, R. N.; Piña-Rodrigues, F. C. M 